Article

\title{
Deriving Optimal End of Day Storage for Pumped-Storage Power Plants in the Joint Energy and Reserve Day-Ahead Scheduling
}

\author{
Manuel Chazarra ${ }^{1, *}$, Juan I. Pérez-Díaz ${ }^{1}$ and Javier García-González ${ }^{2}$ \\ 1 Department of Hydraulic, Energy and Environment Engineering, Escuela de Ingenieros de Caminos, \\ Canales y Puertos, Universidad Politécnica de Madrid, 28040 Madrid, Spain; ji.perez@upm.es \\ 2 Institute for Research in Technology, Technical School of Engineering (ICAI), Comillas Pontifical University, \\ 28015 Madrid, Spain; javiergg@iit.comillas.edu \\ * Correspondence: manuel.chazarra@upm.es; Tel.: +34-616-648-842; ORCID ID: 0000-0003-2221-220X
}

Academic Editor: Ånund Killingtveit

Received: 8 March 2017; Accepted: 9 June 2017; Published: 15 June 2017

\begin{abstract}
This paper presents a new methodology to maximise the income and derive the optimal end of day storage of closed-loop and daily-cycle pumped-storage hydropower plants. The plants participate in the day-ahead energy market as a price-taker and in the secondary regulation reserve market as a price-maker, in the context of the Iberian electricity system. The real-time use of the committed reserves is considered in the model formulation. The operation of the plants with the proposed methodology is compared to the ones that use an end of day storage of an empty reservoir or half of the storage capacity. Results show that the proposed methodology increases the maximum theoretical income in all the plants analysed both if they only participate in the day-ahead energy market and if they also participate in the secondary regulation service. It is also shown that the increase in the maximum theoretical income strongly depends on the size of the plant. In addition, it is proven that the end of day storages change notably in the new reserve-driven strategies of pumped-storage hydropower plants and that the proposed methodology is even more recommended if the secondary regulation service is considered.
\end{abstract}

Keywords: pumped-storage hydropower plants; secondary regulation service; end of day storage; price-maker approach; water value

\section{Introduction}

Closed-loop and daily-cycle pumped-storage hydropower plants (PSHPs) (A closed-loop pumped-storage hydropower plant does not receive natural water inflows in the upper reservoir and does not release water from the lower reservoir. In addition, a daily-cycle pumped-storage hydropower plant is able to empty and refill the upper reservoir in less than $24 \mathrm{~h}$.) have been traditionally operated by the so-called price-arbitrage strategy [1]. The strategy is based on participating in the day-ahead energy market selling energy at peak price hours and purchasing energy at off-peak price hours. The peak/off-peak price hours usually happen in the morning/at night, respectively. In order to maximize the income of the PSHP under the mentioned strategy, the upper reservoir usually starts every day at 0:00 hours empty (to pump water and store energy at night) and finishes the day in the same conditions to fulfil the daily-cycle.

However, nowadays the economic viability of a PSHP might not be guaranteed if they are operated just with the price-arbitrage strategy [2]. Due to this, in the past years, several publications have proposed the PSHPs to participate in other markets and services, apart from the day-ahead energy market, in order to enlarge their income: in the secondary regulation service [3], in the tertiary 
regulation service [4] and in the intraday markets [5]. In this paper, we focus on the participation in the secondary regulation service because it has been little studied [6].

The participation of PSHPs in the secondary regulation service might change the traditional operation strategy [7] as regards the end of day storages: on the one hand, starting the following day empty may not be optimum because the PSHP does not have enough water to participate in the secondary regulation service (If the PSHP participates in the secondary regulation service, enough storage is required to deal with the real-time use of the upward reserves. It is important to note that conventional PSHPs can participate in the secondary regulation service only in generating mode.) and, on the other hand, starting the following day with the upper reservoir full may not be optimum because the PSHP does not have enough storage capacity in the upper reservoir to pump water at low prices of the day-ahead energy market. Therefore, in order to determine the optimum end of day storage, the decision maker should deal with the trade-off between: (1) having sufficient storage capacity if the model decides to pump water; and (2) having sufficient water if the model decides to participate in the secondary regulation reserve market.

The main goals and contributions of this paper are: (i) to propose a methodology to maximize the income and determine the optimal end of day storage of closed-loop and daily-cycle PSHPs participating in the day-ahead energy market (DM) and in the secondary regulation service (SRS) of the Spanish power system; (ii) to quantify the extent to which the proposed methodology can enlarge the maximum theoretical income with respect to the traditional operation strategy; and (iii) to quantify the extent to which the participation of the PSHP in the DM and the SRS can enlarge its maximum theoretical income with respect to the participation only in the DM with the proposed methodology.

The SRS of the Spanish power system comprises two concepts $[8,9]$. The first one is a day-ahead reserve market $(\mathrm{SM})$, which takes place after having cleared the DM and where the upward and downward secondary regulation reserves are assigned, and remunerated according to the same marginal market price. The second one is the secondary regulation energy, i.e., the reserves that are used in real-time by the transmission system operator (TSO) in order to ensure the demand-generation balance. This upward/downward secondary regulation energy is remunerated according to the marginal price of the upward/downward tertiary regulation market. The upward/downward secondary regulation energy represents an income/cost for the PSHP. Note that the procedure for the procurement of the SRS is not exclusive of the Spanish system. A similar procedure is implemented in Norway, Sweden, Finland, Slovenia, Czech Republic and Romania in the short-term (less than a week) and in Denmark, Netherlands, Belgium, Germany, Austria and Switzerland in the long-term (more than a week) [10].

The proposed methodology is based, in part, on the one described in [11,12]. The methodology in [11] uses a look-ahead period of up to six days for the day-ahead energy and reserve scheduling of closed-loop and weekly-cycle PSHPs from a centralized (system-based) point of view. The methodology proposed in this paper makes also use of a look-ahead period for the day-ahead energy and reserve scheduling of closed-loop and daily-cycle PSHPs. Main differences of the presented paper with respect to [11] are: (1) the model here presented is aimed to maximize the income of the PSHP, whereas the one presented in [11] is aimed to reduce the operation cost of the power system; (2) the use in real-time of the committed reserves for the provision of upward and downward secondary regulation energy is considered in this paper; and (3) the proposed methodology is applied for several PSHPs. The work presented in [12] also proposes a methodology similar to the one in [11], with a rolling horizon optimization and a look-ahead period in the context of electricity storage arbitrage in the DM. The main difference of the methodology here presented with respect to the one proposed in [12] is that in the presented paper both energy and reserve are jointly scheduled for the next day. Thus, this paper deals with one of the challenges that was identified in [7] for the operation of PSHPs, as regards the definition of optimal end of day storages in reserve-driven operation strategies of PSHPs.

This paper is organized as follows. Section 2 describes the methodology and model formulation for optimizing the end of day storages. Section 3 presents the case study in which the presented 
methodology is tested. Section 4 shows the results of this research and the discussion of them. Finally, Section 5 presents the main conclusions and the future work.

\section{Derivation of End of Day Storages}

In this paper, two methodologies for the joint day-ahead scheduling of the energy and secondary regulation reserves of a PSHP are compared with each other. The first one considers an end of day storage equal to the initial water volume, as it is usually done in the literature [13], whereas the second one uses a look-ahead period. Hereinafter, the former will be referred to as the methodology without a look-ahead period, and the latter as the one with a look-ahead period. In this context, the look-ahead period refers to the number of hourly steps after a Day D that is considered in the model to decide the optimal energy and reserve schedules in D.

The methodology without a look-ahead period is based on the following (see the upper part of Figure 1). The day-ahead scheduling decisions for Day D are obtained as a result of an optimization problem with a 24-h time horizon, discretized in hourly steps. The initial water volume of the upper reservoir in $\mathrm{D}$ is known by the decision maker, and is usually equal to the minimum one (empty at 0:00), and the final water volume is forced to equal the initial volume in order to fulfill the daily-cycle of the PSHP.
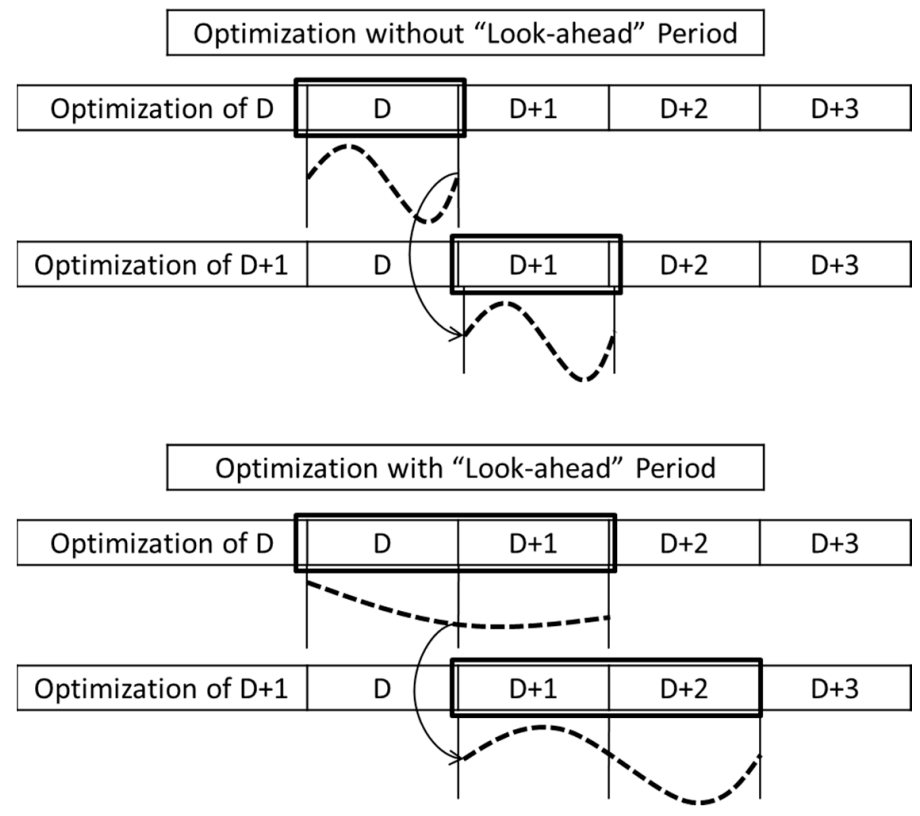

Figure 1. Scheme of the proposed methodology to determine the reservoir initial volume.

The methodology with a look-ahead period uses future information of the electricity power system data and is based on the following (see the lower part of Figure 1). The day-ahead scheduling decisions for Day D are obtained as a result of an optimization problem with a $(24 \times(1+n))$-hour time horizon, i.e., $\mathrm{D}, \mathrm{D}+1, \mathrm{D}+2, \ldots, \mathrm{D}+n$ (with $n>0$ ), also discretized in hourly steps. Note that the lower part of Figure 1 is a particular case of the proposed methodology with one day of look-ahead period, i.e., $n=1$. The initial water volume of the upper reservoir in $\mathrm{D}$ is known by the decision maker, and is obtained as a result of the optimization problem for D - 1. It is important to note that there are no water volume targets at the end of any day $(\mathrm{D}, \mathrm{D}+1, \ldots, \mathrm{D}+n)$.

The above-described methodology with a look-ahead period is conceptually analogous to a water value-based approach because of the size of the PSHPs and the size of the upper reservoir that are considered in this paper: daily-cycle PSHPs, which have a small storage capacity equivalent to few hours (lower or equal $12 \mathrm{~h}$ ) pumping/discharging water at maximum flow. 
The model formulation for both methodologies is based on the one presented in [14], where the impact of the operation of the PSHPs on the market clearing prices of the DM and SM were neglected. Given that the approach presented in [14] assumes a price-taker behavior for both the DM and the SM, the obtained incomes in the SM could be significantly overestimated. In order to overcome this drawback, the model presented in [14] has been conveniently updated in this paper in order to consider the impact in the SM prices of the secondary regulation reserves offered by the PSHP (price-maker approach). The formulation used to model the PSHP as a price-maker is based on the one presented in [15], using a linear approximation of the residual demand curves of the secondary regulation reserve market (RRCs). Note that the PSHPs are modeled as a price-taker in the DM because the maximum power of the analyzed PSHPs (between 400 and $1200 \mathrm{MW}$ ) represents $0.87-2.62 \%$ of the maximum demand of the Spanish system in the said market.

The objective function of the model consists in maximizing the net income in the DM (income due to the sold energy minus cost due to the purchased energy), plus the income for the reserves put at disposal of the TSO in the SM, plus the net income for the secondary regulation energy due to the real-time use of the committed reserves (income/cost due to the real-time use of the upward/downward reserves) and minus the start-up costs in generating and pumping modes. The optimal solution of the model is composed by the hourly schedules in the DM and in the SM, in addition to the hourly schedules of the net secondary regulation energy. Among others, the operation of the PSHPs is restricted to the technical limits of the pump-turbine units and to the maximum and minimum water storage capacity of the upper reservoir.

\section{Case Study}

\subsection{Technical Data}

In the presented paper, nine different PSHPs are studied. They are chosen in order to cover almost all the range of daily-cycle PSHPs: between 4 and $12 \mathrm{~h}$ of empting or refilling the upper reservoir at maximum water discharge and pumped water flow, respectively. The PSHPs are assumed to be equipped with one binary unit operating at fixed speed. A binary unit is composed by a reversible Francis pump-turbine unit and a synchronous motor-generator. The technical data of each PSHP is shown in Table 1. The maximum generation capacity of the $6-12 \mathrm{~h}$ units is close to the one of the largest hydropower units in the world: see [16] for further information about the $805 \mathrm{MW}$ turbine in the Columbia River or see [17] about the 800 MW Francis turbines at the Chinese Xiangjiaba underground hydropower plant. The $4 \mathrm{~h}$ and $5 \mathrm{~h}$ units are also studied for illustrative purposes although their maximum generation capacity is higher. Unpublished results of the authors show that the operation and the economic results are the same for both a $1 \times 1200$ MW PSHP and a $2 \times 600$ MW PSHP.

Table 1. Technical data of each PSHP. $g$ refers to power, $q$ refers to flow and $c S U$ refers to start-up cost. Superscript $d$ refers to generating mode and $p$ refers to pumping mode. Flows are expressed in $\mathrm{m}^{3} / \mathrm{s}$, power in MW and start-up costs in $€$.

\begin{tabular}{ccccccccc}
\hline PSHP & $\bar{q}^{d}$ & $\bar{g}^{d}$ & $q^{d}$ & $g^{d}$ & $\bar{q}^{p}$ & $\bar{g}^{p}$ & $c S U^{d}$ & $c S U^{p}$ \\
\hline 4h & 350.3 & 1200 & 150.6 & 529 & 350.3 & 1573.1 & 3971.1 & 4078.3 \\
5 h & 280.2 & 960 & 1.5 & 423.2 & 280.2 & 1258.5 & 3201.9 & 3287.7 \\
6 h & 233.5 & 800 & 100.4 & 352.7 & 233.5 & 1048.8 & 2689.2 & 2760.7 \\
7 h & 200.2 & 685.7 & 86.1 & 302.3 & 200.2 & 898.9 & 2322.9 & 2384.2 \\
8 h & 175.2 & 600 & 75.3 & 264.5 & 175.2 & 786.6 & 2048.3 & 2101.8 \\
9 h & 155.7 & 533.3 & 66.9 & 235.1 & 155.7 & 699.2 & 1834.6 & 1882.2 \\
$10 \mathrm{~h}$ & 140.1 & 480 & 60.3 & 211.6 & 140.1 & 629.3 & 1663.7 & 1706.5 \\
11 h & 127.4 & 436.4 & 54.8 & 192.4 & 127.4 & 572.1 & 1523.8 & 1562.8 \\
12 h & 116.8 & 400 & 50.2 & 176.3 & 116.8 & 524.4 & 1407.3 & 1443.1 \\
\hline
\end{tabular}


Maximum water discharge and pumped water flow have been chosen in order to empty and refill the upper reservoir in 4-12 hours. Note that the upper reservoir has a storage capacity of $5.0443 \mathrm{M} \cdot \mathrm{m}^{3}$ in all cases. For example, the $6 \mathrm{~h}$ PSHP empties/refills the upper reservoir in six hours at its maximum water discharge/pumped water. The gross head is considered to be $400 \mathrm{~m}$ while the hydraulic losses are considered $3 \%$ of the gross head [18].

In generating mode, the minimum flow and efficiencies at maximum and minimum flows are determined from typical performance curves in [18]. A linear relationship between water discharge and power generation is assumed. As the reversible Francis pump-turbine unit is operated at fixed speed in pumping mode, it has a single operating point with a typical efficiency of $90 \%$ [19]. Start-up costs in generating and pumping modes have been calculated following the guidelines of [20].

\subsection{Electric Power System Data}

The electric power system data used in the presented paper are historical hourly values of the prices of the following markets and services for the year 2014: (i) the day-ahead energy market; (ii) the secondary regulation reserve market; (iii) the upward secondary regulation energy; and (iv) the downward secondary regulation energy. Note that as the PSHPs are modeled as a price-maker in (ii), the data of the secondary regulation reserve market are the historical hourly RRCs. Each historical hourly RRC is linearly approximated and defined by the intercept with the price axis and the slope of the linear approximation, as in [15].

The hourly percentage of the committed upward and downward secondary regulation reserves that is requested in real time by the TSO as upward or downward secondary regulation energy is assumed to be equal to the historical hourly ratio of the aggregate use of the reserves and the aggregate committed reserves in the entire system. Moreover, the hourly ratio between the upward and the total (upward plus downward) reserve offers to be submitted in the SM (expressed as ratio in Table 2) is assumed to be equal to the historical hourly ratio of the upward and total secondary regulation reserve requirements in the entire system. The mean values of the above-mentioned electric power system data throughout 2014 are shown in Table 2.

Table 2. Mean values of the electric power system data of the problem throughout 2014. Energy prices and intercept of the reserve curves are expressed in $€ / M W \cdot h$ and $€ / M W$, respectively. The slope of the reserve curves is expressed in $€ / \mathrm{MW} / \mathrm{MW}$.

\begin{tabular}{ccccccccc}
\hline Year & DM & Intercept RRC & Slope RRC & ER2up & ER2dw & RTURup & RTURdw & Ratio \\
\hline 2014 & 42.15 & 20.09 & -0.0335 & 47.36 & 31.34 & $31.98 \%$ & $22.55 \%$ & $57.13 \%$ \\
\hline
\end{tabular}

\subsection{Methodology}

The optimization model is used to obtain the maximum theoretical income (MTI) with and without the mentioned look-ahead period and with and without participating in the SRS. We use the term MTI to refer to the income that the PSHP would obtain assuming perfect information of the hourly energy prices of the DM, the RRCs of the SM, the percentages of the committed reserves effectively used in real-time and the regulation energy prices of $\mathrm{D}$ and the following days $(\mathrm{D}+1, \mathrm{D}+2, \ldots, \mathrm{D}+n)$.

To obtain the MTI throughout 2014, the model was run, day by day, over the 365 days of the year to: (1) prove that the proposed methodology with a look-ahead period to derive the end of day storage is feasible for realistic PSHPs described in Section 3.1; (2) quantify the extent to which the proposed methodology with a look-ahead period can enlarge the MTI with respect to strategies without look-ahead period; and (3) quantify the extent to which the participation, with the proposed methodology, in the DM and the SRS, can enlarge the MTI with respect to the participation only in the DM. Each problem is solved with a branch and cut algorithm in Cplex in a $2.2 \mathrm{GHz}$ Dual Core AMD Turion CPU, with 4 GB of RAM memory. 
Three operation strategies are compared with each other: (1) the SRS/DM D + 1 strategy uses the methodology proposed in this paper with a 1-day look-ahead period (It is proven in Section 4.1 that the proposed methodology with a look-ahead period of one day is enough to obtain a close to maximum income with a reasonable CPU time consumption, in the context of closed-loop and daily-cycle PSHPs participating in the DM as a price-taker and in the SM as a price-maker.), participating/not participating in the SRS; (2) the SRS/DM V0 strategy, which corresponds to the traditional price-arbitrage strategy [2], uses the methodology without look-ahead period, participating/not participating in the SRS, and starting and finishing each day with the upper reservoir empty; and (3) the SRS/DM Vm strategy is the same as (2) but starting and finishing each day at the mean volume of the storage capacity of the upper reservoir. The mean water volume is chosen in strategy (3) in order to have sufficient storage capacity at the beginning of each day if the model decides to pump water and to have sufficient water at the beginning of each day if the model decides to participate in the SRS.

\section{Results and Discussion}

\subsection{Length of the Look-Ahead Period}

The results shown in Figure 2 and Table 3 provide insight on the length of the look-ahead period that allows obtaining a close to maximum income with a reasonable CPU time consumption. In Figure 2, the MTIs of each PSHP participating in the DM and the SRS without (SRS D) and with different look-ahead periods (1-3 days) are shown (SRS D + 1, SRS D + 2, SRS D + 3). In addition, the mean CPU time consumption per problem in each case is also shown (Time $\mathrm{D}$, Time $\mathrm{D}+1$, Time $\mathrm{D}+2$, Time $\mathrm{D}+3$ ). In this comparison, the model without look-ahead period assumes that the upper reservoir is empty at the beginning and the end of each day.

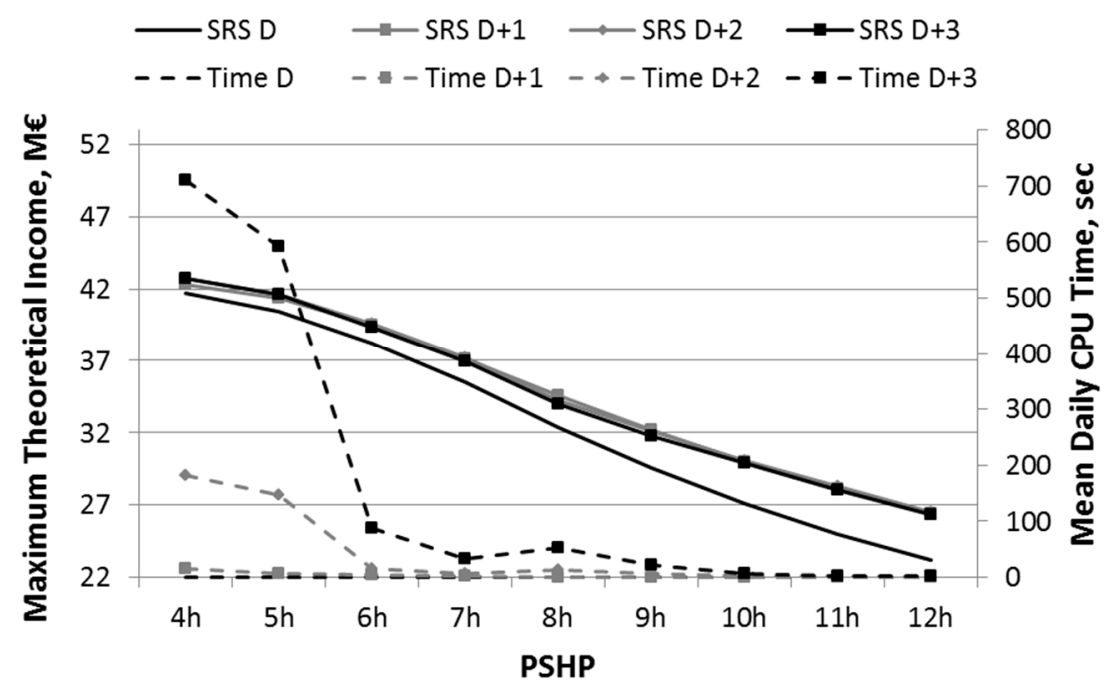

Figure 2. Annual maximum theoretical income, in millions of $€$, and the mean CPU time consumption of each daily problem, in seconds, for $n$ days of look-ahead period and without look-ahead period.

Table 3. Mean CPU time consumption of each daily problem, in seconds, for $n$ days of look-ahead period.

\begin{tabular}{cccccccccc}
\hline Strategy & $\mathbf{4 h}$ & $\mathbf{5} \mathbf{h}$ & $\mathbf{6} \mathbf{h}$ & $\mathbf{7} \mathbf{h}$ & $\mathbf{8} \mathbf{h}$ & $\mathbf{9 h}$ & $\mathbf{1 0} \mathbf{h}$ & $\mathbf{1 1} \mathbf{h}$ & $\mathbf{1 2} \mathbf{h}$ \\
\hline Time D & 1.0455 & 0.7792 & 0.7003 & 0.6214 & 0.5819 & 0.5129 & 0.5227 & 0.4833 & 0.4438 \\
Time D + 1 & 16.18 & 7.49 & 3.82 & 1.75 & 1.11 & 0.82 & 1.09 & 0.66 & 0.57 \\
Time D + 2 & 183.05 & 147.86 & 15.79 & 7.75 & 13.99 & 7.11 & 2.3 & 1.51 & 1.23 \\
Time D + 3 & 709.5 & 591.5 & 88.5 & 33.2 & 53.3 & 22.2 & 6.4 & 3.2 & 3.2 \\
\hline
\end{tabular}


As expected, the more days that are considered in the look-ahead period, the higher the mean daily CPU time consumption is. Nevertheless, the annual MTIs are not always higher. For example, in the $4 \mathrm{~h}$ and $5 \mathrm{~h}$ PSHPs, the mean daily CPU time consumption is $183 \mathrm{~s}$ and $147 \mathrm{~s}$ for D +2 , respectively, whereas if one extra day is considered in the look-ahead period (i.e., D + 3), the CPU time consumption increases up to $709 \mathrm{~s}$ and $591 \mathrm{~s}$, respectively. However, the annual MTI slightly decreases (42.75 to 42.7 $\mathrm{M} €$ and 41.63 to $41.58 \mathrm{M} €$, respectively).

The mean daily CPU time consumption of the $4-12 \mathrm{~h}$ PSHPs is more clearly shown in Table 3. The differences in seconds of the CPU time consumption between the cases without look-ahead period (Time D) and with one day of look-ahead period (Time D +1 ) are not significant. However, as can be seen in Figure 2, the annual MTIs with one day of look-ahead period (SRS D + 1) are higher than without look-ahead period (SRS D) for all PSHPs. Regarding the results considering two or three days of look-ahead period, Table 3 confirms that the increase in the CPU time consumption is not always justified by the one in the annual MTI. For example, the $12 \mathrm{~h}$ PSHP increases $13.8 \%$ the MTIs (from 23.2 M€ to $26.41 \mathrm{M} €$ ) if one day of look-ahead period is considered, increasing slightly the CPU time consumption (from $0.44 \mathrm{~s}$ to $0.57 \mathrm{~s}$ per day). However, if three days of look-ahead period are considered, the MTIs decrease from 26.41 M€ to $26.33 \mathrm{M} €$, increasing the mean daily CPU time consumption (from $0.57 \mathrm{~s}$ to $3.23 \mathrm{~s}$ ).

As a conclusion, in the context of closed-loop and daily-cycle PSHPs participating in the DM as a price-taker and in the SM as a price-maker, it seems to be enough to consider a look-ahead period of one day. This is because the increase of the mean daily CPU time consumption for considering longer look-ahead periods (two or three days) does not imply an increase of the annual MTI for any analyzed PSHP.

\subsection{Maximum Theoretical Income}

The MTIs of all PSHPs under each above-described strategy (SRS/DM D + 1/V0/Vm) are presented in Figure 3. See Section 3.3 for further details of each strategy.

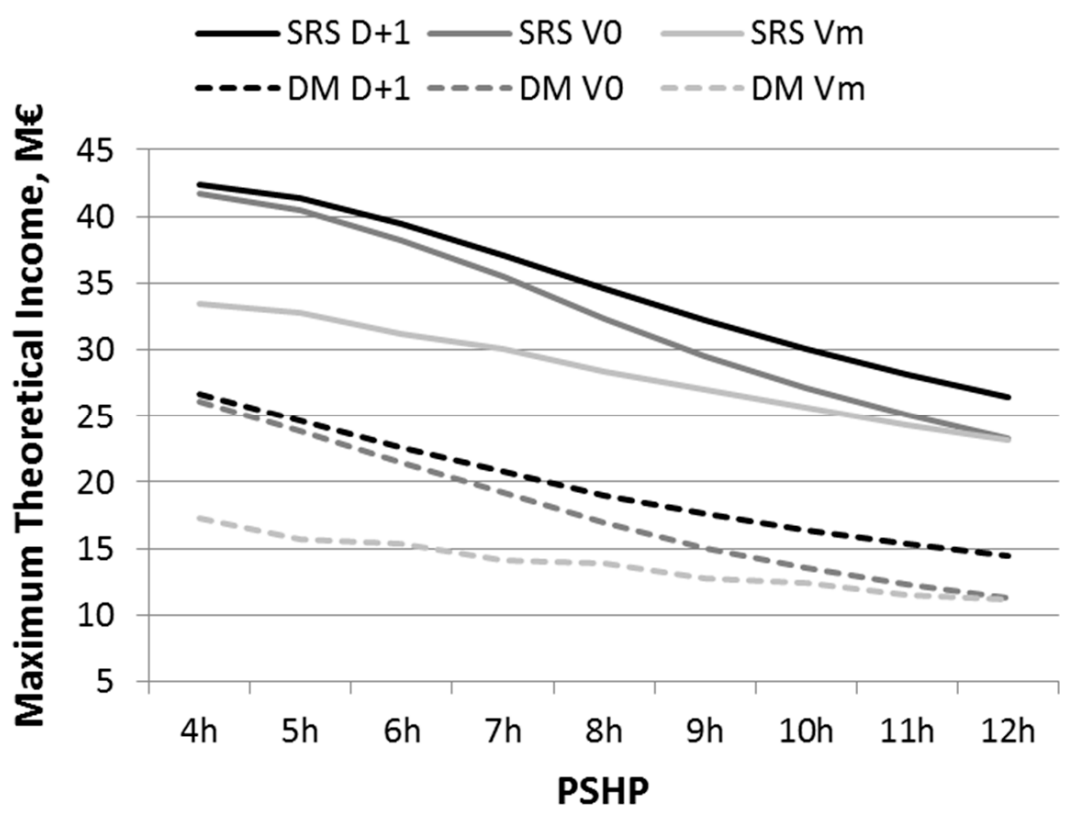

Figure 3. Annual maximum theoretical income, in millions of $€$, of each PSHP participating in the DM and the SRS (solid lines) and only in the DM (dashed lines).

The strategy that obtains the highest MTIs is the SRS D + 1, followed by the SRS V0 and, finally, the SRS Vm. The SRS D + 1 increases the MTI by $1-14 \%$ and by $519-8012 € / M W$ of installed 
capacity in generating mode with respect to the SRS V0 and by $14-27 \%$ and by $7443-10,388 €$ / MW with respect to the SRS Vm. Note that the increase in the maximum theoretical income strongly depends on the size of the plant. The highest economic differences between the SRS D + 1 and the SRS V0 occur in the $12 \mathrm{~h}$ PSHP and between the SRS V0 and the SRS Vm in the $4 \mathrm{~h}$ PSHP.

Similar trends can be seen in the economic results with the DM D + 1, DM V0 and DM Vm strategies. Differences appear in the relative increases between strategies: the DM D + 1 strategy obtains $2.1-27 \%$ and $455-7798 € / \mathrm{MW}$ of installed capacity in generation mode higher MTIs than the DM V0 and $29-57 \%$ and 7770-9645 €/MW higher MTIs than the DM Vm.

Furthermore, from the results shown in Figure 3, one can conclude that the participation in the SRS is strongly recommended. An increase of the MTIs is remarkable in all the considered strategies when the PSHP participates in the SRS. With the SRS/DM D + 1 strategies, the MTIs increase by $59-84 \%$ when the PSHP participates in the SRS; with the SRS/DM V0 strategies, by 60-106\%; and with the SRS/DM Vm strategies, by $93-111 \%$. Although the relative increase between strategies is quite different, the absolute increase (measured in $€$ ) is analogous.

Finally, if the comparison is carried out between PSHPs, it can be seen in Figure 3 that the MTI monotonically decreases as the number of hours increases (4-12 h), or as the installed capacity of the PSHP decreases (1200-400 MW): the $4 \mathrm{~h} / 12 \mathrm{~h}$ PSHP obtains the highest/lowest MTI in absolute numbers. However, if the same comparison is carried out with the MTI per MW of installed capacity in generating mode, the results are exactly the opposite (see Figure 4). Except with the DM V0 strategy, the MTI per MW monotonically increases as the number of hours increases (4-12 h), or as the installed capacity of the PSHP decreases (1200-400 MW): the 4 h/12 h PSHP obtains the lowest/highest MTI per MW of installed capacity.

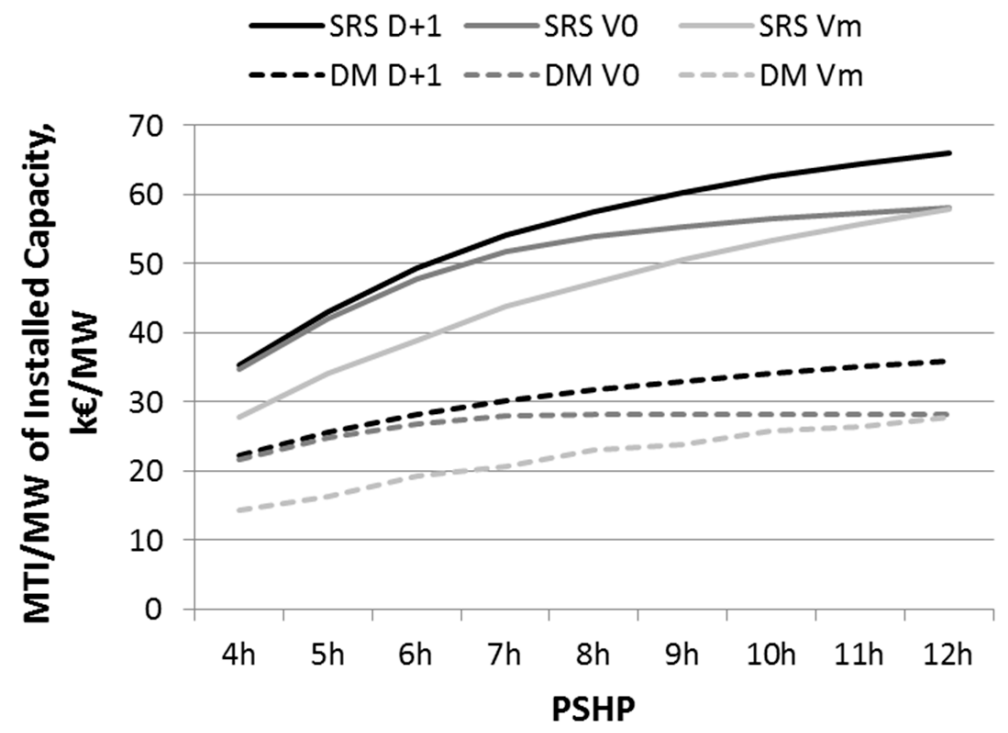

Figure 4. Annual maximum theoretical income (MTI) per MW of the installed capacity in generating mode, of each PSHP participating in the DM and the SRS (solid lines) and only in the DM (dashed lines).

The incomes and costs obtained with the SRS D + 1 strategy is distributed among the considered markets and services as shown in Table 4. It shows the net income in the DM, i.e., the income for selling energy in generating mode ( $\mathrm{DM}+)$ minus the cost for purchasing energy in pumping mode (DM-), the income in the SM, the income for the real-time use of the upward reserves (ER2up), the cost for the real-time use of the downward reserves (ER2dw), the start-up costs in generating mode $\left(c S U^{d}\right)$ and in pumping mode $\left(c S U^{p}\right)$ and, finally, the profit of the operation of the PSHPs (Total). 
Table 4. Annual incomes and costs, expressed in M€, obtained by all the PSHPs in each market and service with the SRS D + 1 strategy.

\begin{tabular}{cccccccccc}
\hline PSHP & DM+ & DM - & DM & SM & ER2up & ER2dw & $c S U^{d}$ & $c S U^{p}$ & Total \\
\hline 4 h & 107.29 & -73.21 & 34.08 & 15.7 & 5.9 & -8 & -3.11 & -2.24 & 42.33 \\
$5 \mathrm{~h}$ & 101.69 & -72.45 & 29.24 & 17.97 & 6.24 & -7.6 & -2.72 & -1.78 & 41.36 \\
$6 \mathrm{~h}$ & 93.87 & -68.2 & 25.67 & 18.58 & 5.94 & -6.9 & -2.34 & -1.49 & 39.47 \\
$7 \mathrm{~h}$ & 86.7 & -63.95 & 22.75 & 18.38 & 5.56 & -6.26 & -2.04 & -1.29 & 37.1 \\
$8 \mathrm{~h}$ & 79.31 & -58.81 & 20.5 & 17.53 & 5.13 & -5.67 & -1.78 & -1.17 & 34.53 \\
9 h & 72.68 & -54.16 & 18.52 & 16.64 & 4.78 & -5.13 & -1.6 & -1.06 & 32.16 \\
$10 \mathrm{~h}$ & 66.78 & -49.59 & 17.19 & 15.5 & 4.34 & -4.66 & -1.39 & -0.95 & 30.03 \\
$11 \mathrm{~h}$ & 61.75 & -45.96 & 15.8 & 14.65 & 4.03 & -4.27 & -1.23 & -0.87 & 28.1 \\
$12 \mathrm{~h}$ & 57.64 & -42.86 & 14.78 & 13.79 & 3.74 & -3.96 & -1.13 & -0.81 & 26.41 \\
\hline
\end{tabular}

The main income source is the DM, representing $56-80 \%$ of the MTI for the $12-4 \mathrm{~h}$ PSHP, respectively (Table 4). This result contradicts one of the conclusions of [21] and [22], where it was stated that the SM is the main income source in the operation of PSHPs participating in the DM and the SRS. The main reason of the presented result in comparison to the one published in the literature is that, in this paper, the effect of the reserve schedule in the clearing price of the SM is taken into account (price-maker approach in the SM). Hence, the income in the SM with respect to the total is less representative than the one in the DM (between $37 \%$ and $52 \%$ of the MTI for the $4-12 \mathrm{~h} \mathrm{PSHP}$, respectively). Note that the lower the installed capacity of the PSHP, the higher the income in the SM in relative terms of the MTI, because the impact in the marginal price of the SM is lower.

The economic results of each PSHP with each SRS strategy are presented for the DM in Figure 5, for the SM in Figure 6 and for the secondary regulation energy in Figure 9. The results for the DM strategy are not presented in Figure 5 because they are similar to Figure 3 but subtracting only the start-up costs, and are not presented in Figure 6 and Figure 9 because the SRS does not apply.

From the point of view of the participation in the DM, the SRS D + 1 strategy obtains the highest income (left y-axis in Figure 5) and income per MW of installed capacity (right y-axis in Figure 5) for all PSHPs, following a similar tendency as the MTI in Figure 3 and the MTI per MW of installed capacity in Figure 4, respectively.

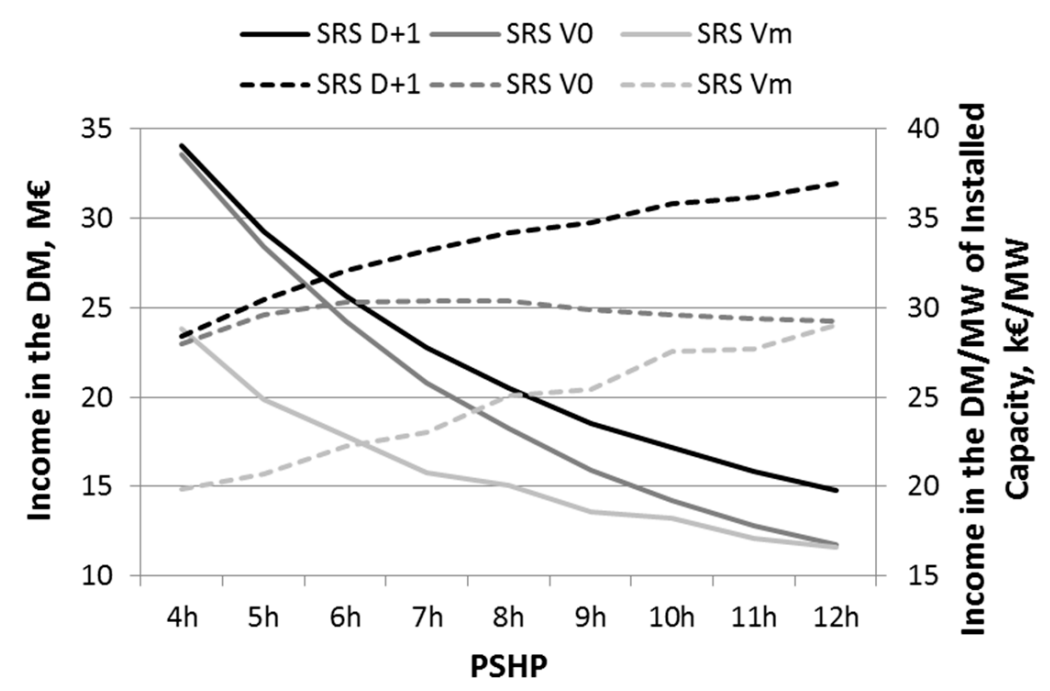

Figure 5. Annual maximum theoretical income in the DM (solid lines) and per MW of the installed capacity in generating mode (dashed lines) of each PSHP.

Regarding the economic results in the SM, the MTIs of each PSHP with the SRS D + 1, SRS V0 and SRS Vm strategies are shown on the left y-axis of Figure 6 and the MTIs per MW of the installed 
capacity in generating mode are shown on the right y-axis. Notice that the MTIs and the MTIs per MW in the SM do not change significantly between strategies for each PSHP. The behavior of the MTI in the SM per MW is analogous to the one of the MTI per MW of the installed capacity (Figure 4) or to the MTI in the DM per MW of installed capacity (Figure 5): monotonically increasing as the number of hours increases (4-12 h) or as the installed capacity of the PSHPs decreases (1200-400 MW).

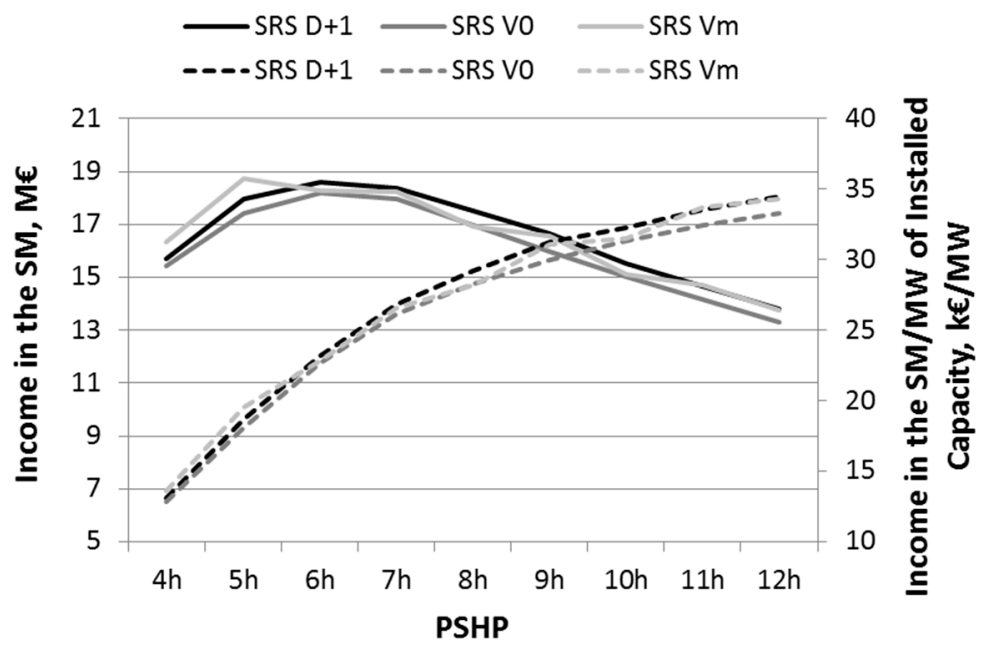

Figure 6. Annual maximum theoretical income in the SM (solid lines) and per MW of the installed capacity in generating mode (dashed lines) of each PSHP.

It is interesting to note that the MTI in the SM (left y-axis of Figure 6) does not monotonically decrease with the number of hours necessary to empty the upper reservoir as in the DM (left y-axis of Figure 5). The higher the installed capacity of the PSHP, the higher the MTI in the SM, up to a certain level of installed capacity (up to the $6 \mathrm{~h}$ PSHP). The $4 \mathrm{~h}$ and $5 \mathrm{~h}$ PSHPs obtain less income in the SM in comparison to the $6 \mathrm{~h}$ PSHP. This result can be explained by a combination of two aspects: firstly, the effects of the price-maker approach; and secondly, the number of hours in which the PSHPs participate in the DM generating energy and, therefore, in the SRS. The former is explained with Figure 7. It shows the mean hourly energy generation in the DM and the mean hourly secondary regulation reserves (upward plus downward reserves), in the left y-axis. The mean hourly values are obtained only using the hours in which the PSHPs participate in the DM and the SM, respectively. Besides, it is also shown, in the right y-axis of Figure 7, the percentage of the mean hourly energy generation in the DM and reserves in the SM with respect to the operating range (maximum minus minimum power) and with respect to the available reserves, respectively. One hundred/zero percentage means a mean hourly energy generation in the DM of maximum/minimum power and a mean hourly reserve in the SM of maximum/zero reserve availability, respectively. For example, the $8 \mathrm{~h}$ PSHP has a mean hourly energy generation in the DM of $41 \%$ of the operating range and mean hourly total reserves offered in the SM of $96 \%$ of the available ones (Most PSHPs have a mean hourly energy generation in the DM of $40 \%$ of the operating range. One reason for this is the rules of the SM in the Spanish electricity system. The bids submitted to the SM have to fulfill a ratio between the upward and downward secondary regulation reserves. The mean hourly ratio in 2014 was $57.13 \%$ and $42.87 \%$ for the upward and downward reserves, respectively). It can be seen in Figure 7 that the $4 \mathrm{~h}$ and $5 \mathrm{~h}$ PSHPs have more available reserves than the optimum because they offer less $(83 \%$ and $90 \%$ of the available reserves, respectively) in comparison to the rest of PSHPs (between $93.4 \%$ and $96 \%$ ). As mentioned above, the reason to this is the effects of the price-maker approach: the higher the bids presented in the SM, the higher the cleared price reduction. 


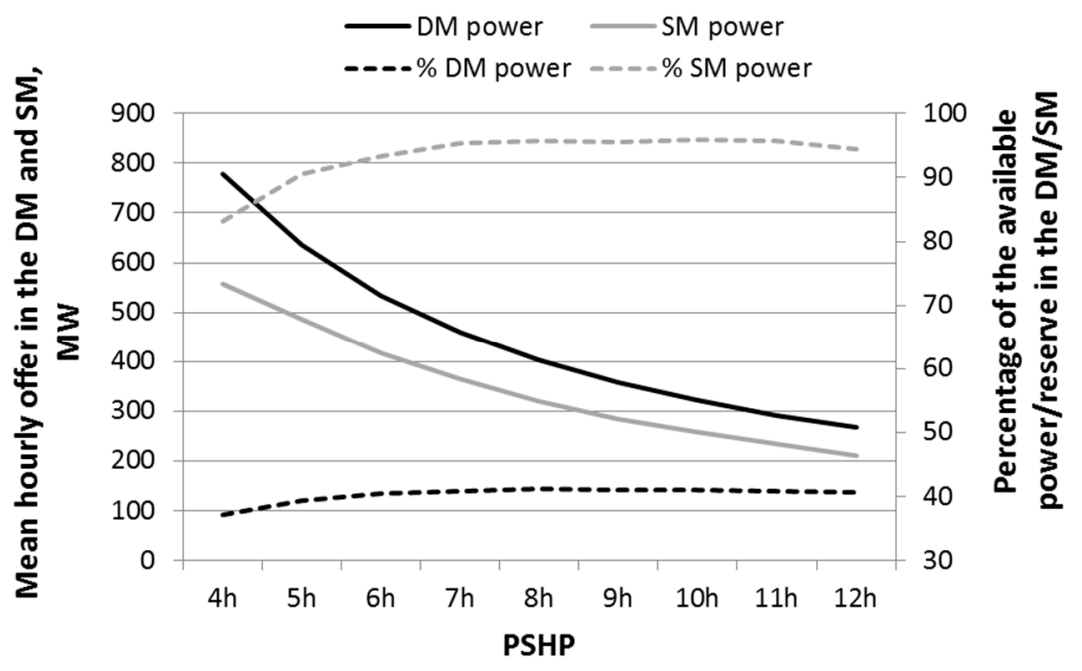

Figure 7. Mean hourly power generation in the DM/total reserves offered to the SM, for each PSHP (black/grey solid lines) and percentages of the total available power in the DM/reserve to the SM (black/grey dashed lines).

The above-mentioned second aspect that explains that the MTI in the SM (left y-axis of Figure 6) does not monotonically decrease is the number of hours in which the PSHPs participate in the DM and, therefore, in the SRS. This is explained with Figure 8. It shows the mean daily hours in which the PSHPs generate/consume energy in the DM with the SRS D + 1 strategy (Gen/Cons SRS) and with the DM D + 1 strategy (Gen/Cons DM). It is important to note that the PSHPs participate in the SM in the $99 \%$ of hours in which they generate energy in the DM.

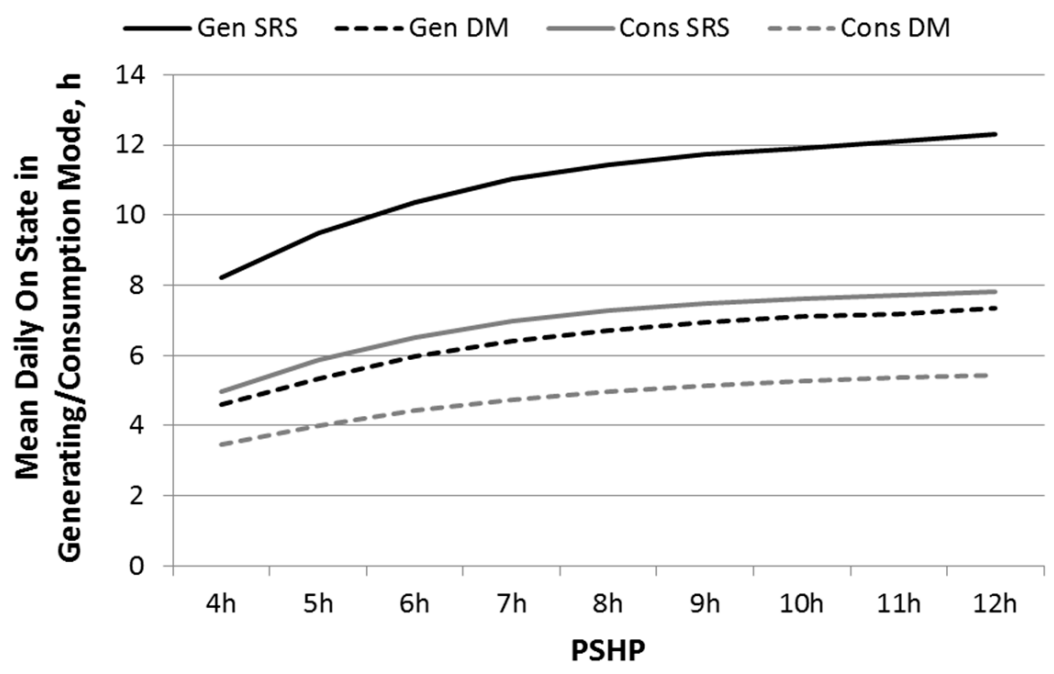

Figure 8. Mean daily hours generating/consuming energy each PSHP participating in the DM and the SRS (black/grey solid lines) and participating only in the DM (black/grey dashed lines).

The $4 \mathrm{~h}$ and $5 \mathrm{~h}$ PSHPs are the ones that participate in the DM generating energy fewer hours and, therefore, they will participate in the SRS fewer hours. However, they prefer to reduce the generation energy in the DM down to 37\% and 39\%, respectively, of the operating range (Figure 7) to increase the number of hours that they participate in the DM and, therefore, in the SRS (to enlarge their income). This is confirmed by comparing the mean daily number of hours of the $4 \mathrm{~h}$ and $12 \mathrm{~h}$ PSHPs generating energy in the DM: $8 \mathrm{~h}$ and $12 \mathrm{~h}$, respectively. 
In addition, it can be seen in Figure 8 that all PSHPs generate and consume in the DM during more hours, as a mean, if they participate in the DM and the SRS in comparison to only participate in the DM. The reason to this is the inclusion of the SRS: the more hours generating energy in the DM, the more hours the PSHPs can participate in the SRS and, therefore, they are able to enlarge their income. In order to generate energy during more hours, the PSHPs are able to consume energy during more hours and/or reduce the power generation in each hour. This is confirmed by Figure 8: the increase in the number of hours in which the PSHPs are generating energy due to the inclusion of the SRS is higher than the increase when the PSHPs are consuming energy.

Finally, the economic results of the income/cost due to the real-time use of the upward/downward secondary regulation reserves (Figure 9) are similar between strategies. The monotonically decrease of the ER2up income seems to be broken in the $4 \mathrm{~h}$ PSHP because of the above-mentioned aspects: the effects of the price-maker approach in the SM and the number of hours in which the PSHPs participate in the DM generating energy and, therefore, in the SRS (Figures 7 and 8).

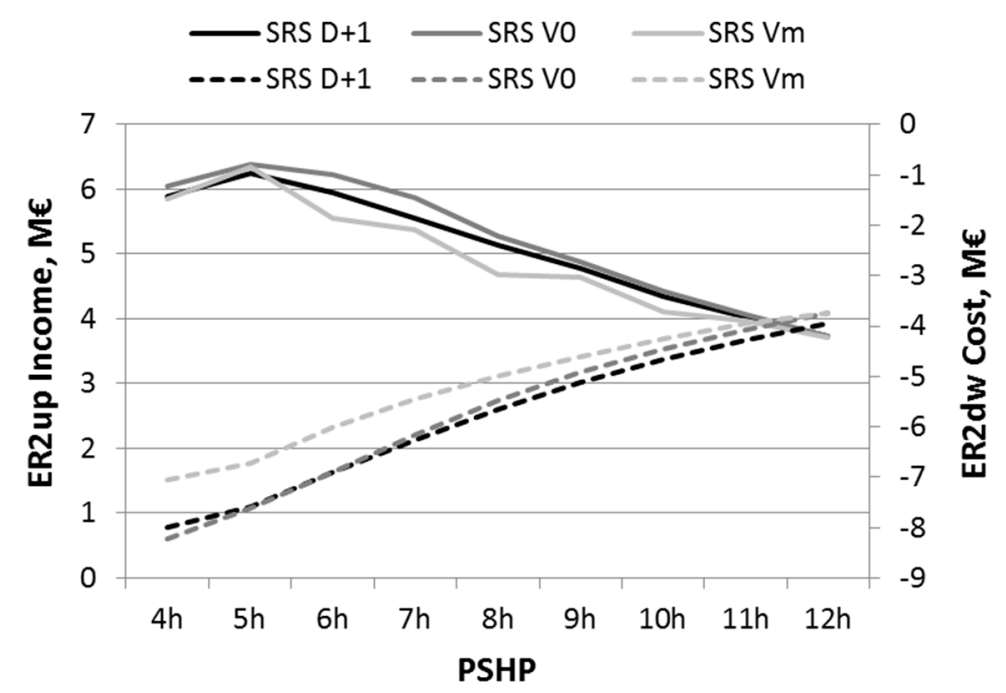

Figure 9. Annual maximum theoretical income due to the real-time use of the upward (ER2up, solid lines) and the downward (ER2dw, dashed lines) reserves of each PSHP.

\subsection{End of Day Storage}

The histograms of the end of day storage for each PSHP participating in the DM, and in the DM and the SRS can be seen in Figures 10 and 11, respectively. Note that these results are obtained with the DM D + 1 and the SRS D + 1 strategies, respectively.

The most frequent end of day storage interval is the one that is closer to zero, regardless whether the PSHP participates only in the DM or in the DM and the SRS. However, the number of days in which the end of day storage is in the mentioned interval is higher if the PSHP participates in the DM than if it participates in the DM and the SRS (for example, 293 days if the $4 \mathrm{~h}$ PSHP only participates in the DM whereas 236 days if it participates in the DM and the SRS).

In addition to this, the water volume interval that is closer to the maximum storage has a higher number of days if the PSHPs only participate in the DM than if they also participate in the SRS. The main reason for this is the relative values of the price profiles of the DM between $\mathrm{D}$ and $\mathrm{D}+1$. If the price profile for the following day is higher in most of the hours with respect to the current day, the model is able to: (i) mostly pump water during the current day; (ii) finish the day as full as possible and (iii) generate energy the following day. To illustrate this, an example for 2-3 June 2014 with the DM D +1 and the SRS D +1 strategies and the $4 \mathrm{~h}$ PSHP are presented in Figures 12 and 13, respectively. 

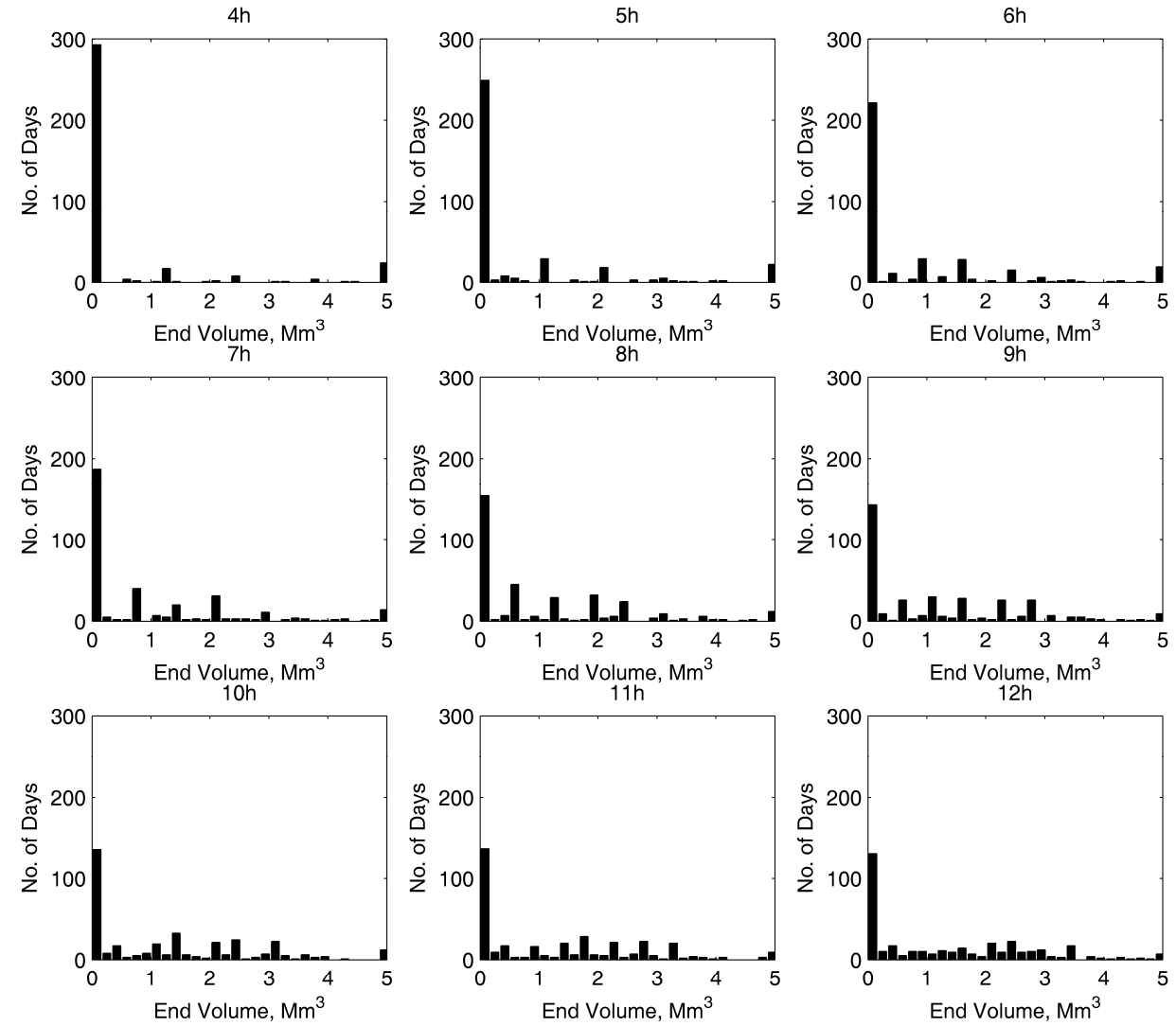

Figure 10. Histogram of the end of day volumes for each PSHP participating in the DM.
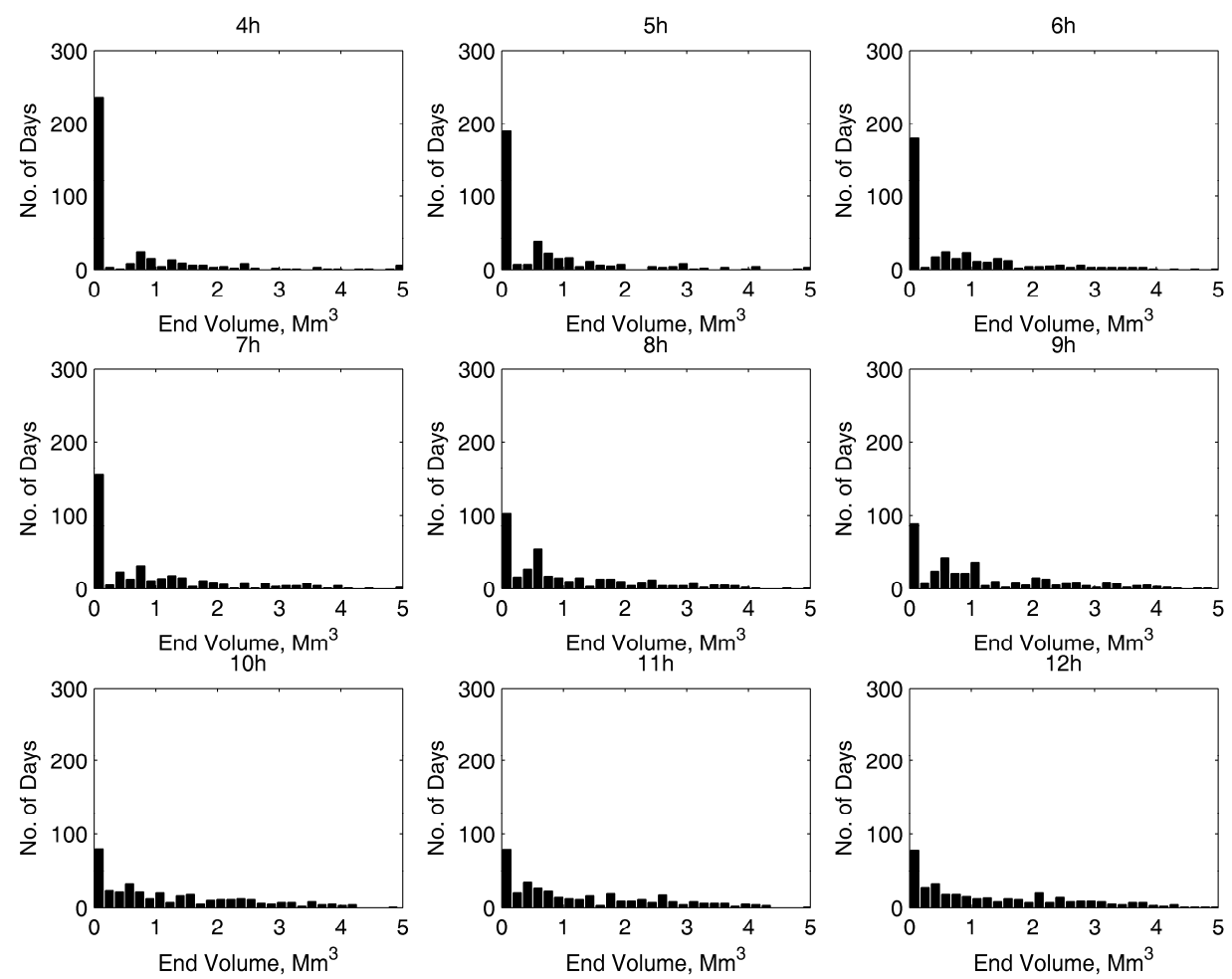

Figure 11. Histogram of the end of day volumes for each PSHP participating in the DM and SRS. 
Figure 12 is divided into two subfigures where the following variables are depicted. The upper subfigure shows the water volume trajectory of the upper reservoir in solid line and the total water through the turbines (positive) or pumps (negative) in bars. The lower subfigure shows the energy schedule in the DM in bars and the price of the DM in solid line. Figure 13 is divided into three subfigures. The two first are the same as in Figure 12. In the lower subfigure of Figure 13, the following variables are depicted: the secondary regulation reserve schedule in bars and the price of the SM in solid line, which takes into account the reduction due to the presented bids of the agent (price-maker effects). The water volume at hour 24 changes significantly if the SRS is included $\left(1.23 \mathrm{Mm}^{3}\right)$ or not $\left(5.04 \mathrm{Mm}^{3}\right)$. In the latter, the model decides to pump water at hours 3-5 and, instead of generating energy at peak hours of the DM in D, it is carried out at peak hours of the DM in D + 1 (at hours 32-38). The energy schedule significantly changes if the PSHP also participate in the SRS: the model decides to pump water at the same hours 3-5 in D but instead of keeping the water for the following day, it decides to generate energy at hours 7-11 and 23, also participating in the SRS. Due to this, it finishes the day at a much lower water volume than with the DM D + 1 strategy. In order to participate again in the SRS the following day, the model pumps water at hours 28-29, and generates energy and participates in the SRS at hours 31-35. This confirms that the importance of the price-arbitrage in the DM decreases if the SRS is deemed.
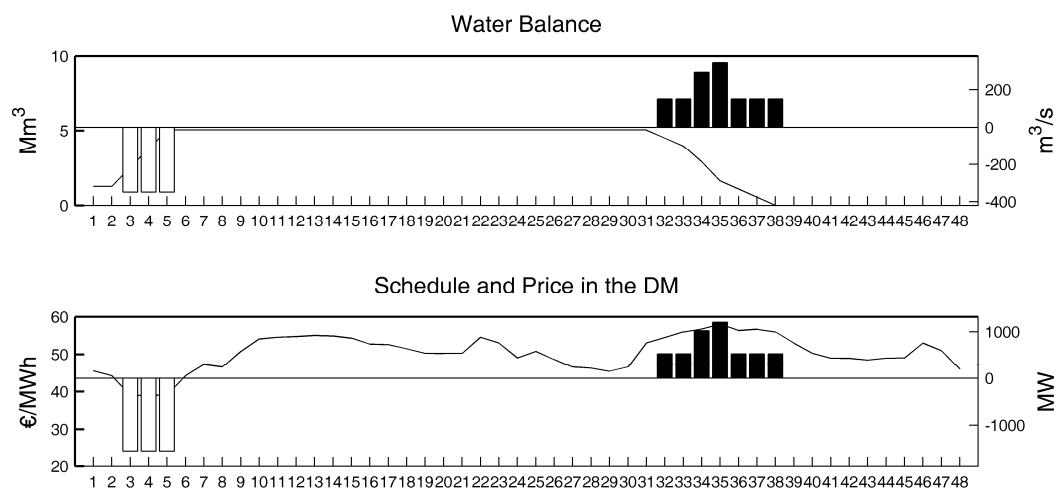

Figure 12. Optimal operation of the $4 \mathrm{~h}$ PSHP with the DM D + 1 strategy on 2-3 June 2014.
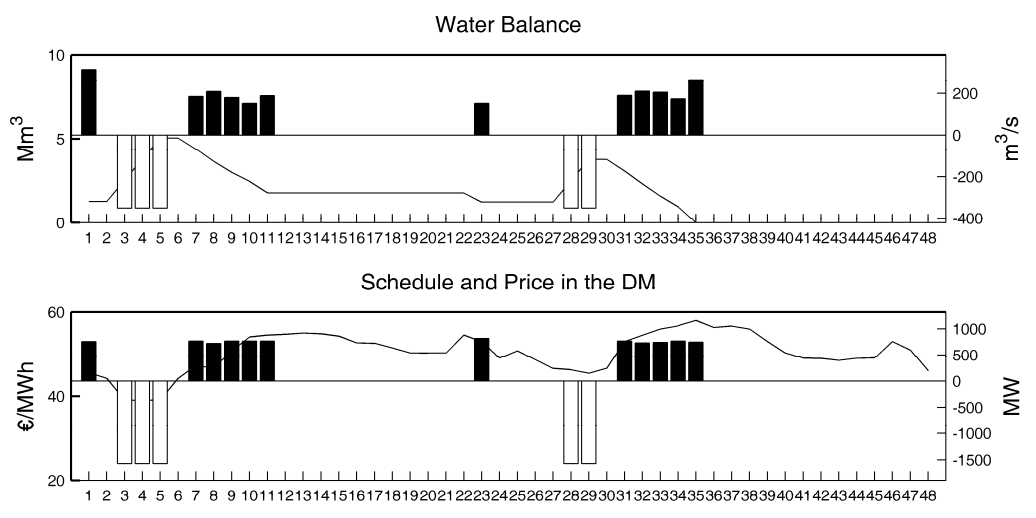

Schedule and Price in the SM

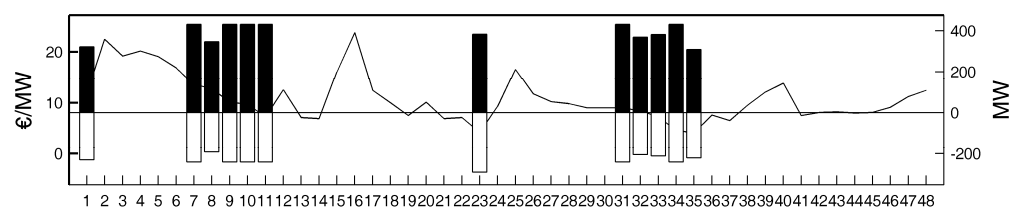

Figure 13. Optimal operation of the $4 \mathrm{~h}$ PSHP with the SRS D + 1 strategy on the 2-3 June 2014. 
As a conclusion, comparing Figures 10 and 11, the end of day storage if the PSHPs also participate in the SRS have a less extreme behavior (less number of days in the interval closer to zero and to the maximum) with respect to the ones if the PSHPs only participate in the DM. Hence, it is proven that the end of day storage change notably in the new reserve-driven strategies of PSHPs.

As a future work, the authors would like to analyze the impact that the variable speed technology or the operation in hydraulic short-circuit mode has in the operation of PSHPs with the DM D + 1 and, especially, with the SRS D + 1 strategies. The variable speed technology and the operation in hydraulic short-circuit mode permit the PSHPs to regulate power in pumping mode and, hence, to also participate in the SRS at hours in which the PSHPs are consuming. As shown in Figure 13, the PSHP cannot participate in the SRS at hours 3-5 and 28-29 because, in this paper, PSHPs with fixed speed are deemed.

Finally, the importance of the proposed methodology with a look-ahead period (DM D + 1 and SRS $\mathrm{D}+1$ strategies) is also confirmed by the results obtained in Figures 14 and 15. They show the histograms of the deviations with respect to the traditional price-arbitrage operation, i.e., the deviations between the total pumped and discharged water volumes, with the DM D +1 and SRS D + 1 strategies, respectively. A positive/negative deviation means that in a certain day, there is more pumped/discharged water than discharged/pumped water. The traditional price-arbitrage operation starts and finishes each day with the same water volume. Thus, it would obtain zero deviation in all days.

The most frequent deviation interval is the one that is closer to zero, regardless whether the PSHP participates only in the DM or in the DM and the SRS. However, similarly as it was observed in Figures 10 and 11 with the end of day storage, the number of days in which the deviations are in the mentioned interval is higher if the PSHP participates in the DM than if it participates in the DM and the SRS (for example, 256 days if the $4 \mathrm{~h}$ PSHP only participates in the DM whereas 175 days if it participates in the DM and the SRS). If Figures 14 and 15 are compared, the histograms of the deviations with the SRS D + 1 strategy have a more weighted tails in comparison to the ones of the DM D + 1 strategy. This result confirms that the traditional price-arbitrage strategy, which is restricted to meet the daily-cycle, is not the optimum and that the operation strategies with a look-ahead period are even more recommended if the SRS is considered.
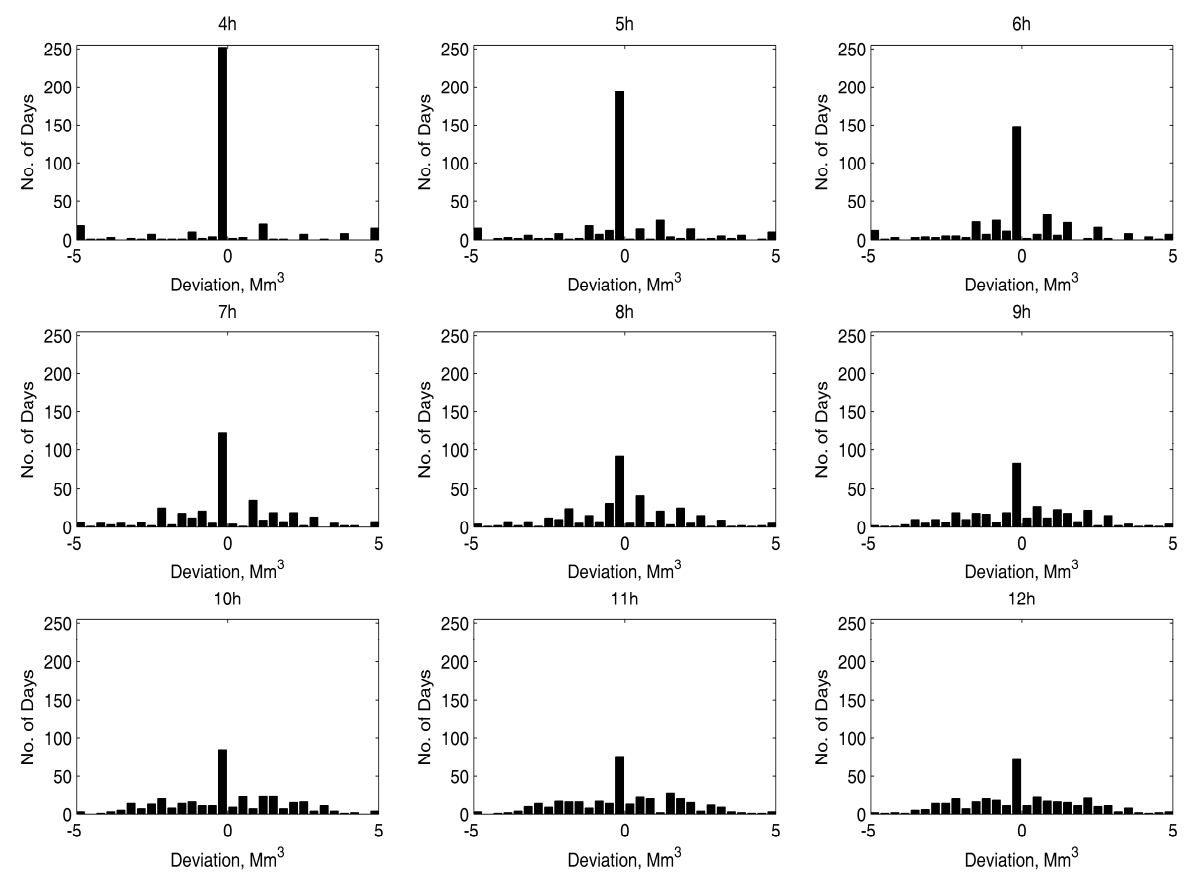

Figure 14. Histogram of the deviations with respect to the daily-cycle operation, of each PSHP participating in the DM. 

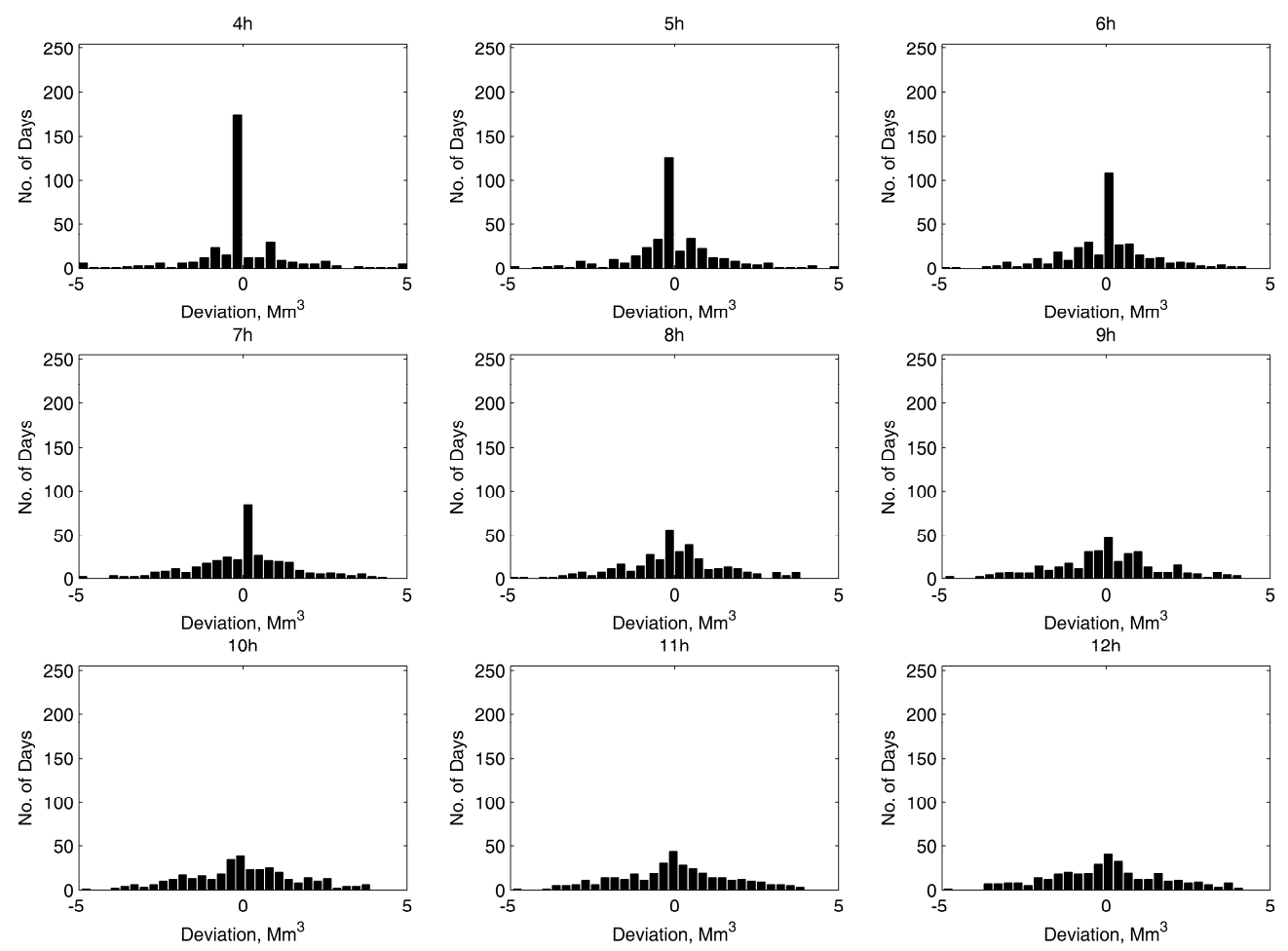

Figure 15. Histogram of the deviations with respect to the daily-cycle operation, of each PSHP participating in the DM and the SRS.

\section{Conclusions}

A new methodology to maximize the income and determine the optimal end of day storage of closed-loop and daily-cycle pumped-storage hydropower plants participating in the day-ahead energy and the secondary regulation reserve markets is presented in this paper. It uses a look-ahead period with future information of the electricity power system data. The plants participate in the day-ahead energy market as a price-taker and in the secondary regulation reserve market as a price-maker. The real-time use of the committed reserves is also considered in the model formulation. The results obtained in the paper indicate that using a look-ahead period of one day is sufficient to highly increase the income without a significant increase in the CPU time consumption. Furthermore, the proposed methodology enlarges the annual maximum theoretical income of the plants between 455 and $9645 € / \mathrm{MW}$ of the installed capacity if they only participate in the day-ahead energy market and between 519 and $10388 € / \mathrm{MW}$ of installed capacity if they also participate in the secondary regulation reserve service, in comparison to methodologies without a look-ahead period. The relative increase in the maximum theoretical income strongly depends on the size of the plant. Finally, it has been proven that the end of day storage has a less extreme behavior in the new reserve-driven strategies of pumped-storage hydropower plants. Therefore, the hourly scheduling tools of closed-loop and daily-cycle pumped-storage hydropower plants that only consider the day-ahead energy market or do not use a look-ahead period might deviate notably from the optimal operation.

As a future work, the authors would like to study the following issues: (1) the extent to which the proposed methodology is able to enlarge the plant income without assuming perfect knowledge of the electricity power system data; (2) the impact of the proposed methodology in the operation of pumped-storage hydropower plants operating with variable speed or in hydraulic short-circuit mode; and (3) the impact in the end of day storage of the participation of pumped-storage hydropower plants in other markets (such as the intraday market) or in other ancillary services (such as the tertiary regulation service). 
Acknowledgments: This work was supported by the Spanish Ministry of Economy and Competitiveness under the project "Optimal operation and control of pumped-storage hydropower plants" of The National Scientific Research, Development and Technological Innovation Plan 2008-2011 (Ref. ENE2012-32207).

Author Contributions: Manuel Chazarra was involved in conceiving the methodology presented in the paper, formulating the scheduling model, gathering the electric power system data and obtaining the results. Juan Ignacio Pérez-Díaz was involved in conceiving the methodology presented in the paper. Manuel Chazarra wrote the manuscript. Juan Ignacio Pérez-Díaz and Javier García-González contributed to the integrity of the work as a whole. Finally, all the authors have been involved in the analysis of the results and the obtaining of the conclusions.

Conflicts of Interest: The authors declare no conflict of interest.

\section{Nomenclature}

DM Day-ahead energy market

ER2up Upward secondary regulation energy, i.e., the real-time use of the upward committed reserves

ER2dw Downward secondary regulation energy, i.e., the real-time use of the downward committed reserves

MTI Maximum theoretical income

PSHP Pumped-storage hydropower plant

RRC Residual reserve curve, i.e., the residual demand curve of the secondary regulation reserve market

SM Secondary regulation reserve market

SRS Secondary regulation service

TSO Transmission system operator

\section{References}

1. Graves, F.; Jenkin, T.; Murphy, D. Opportunities for electricity storage in deregulating markets. Electr. J. 1999, 12, 46-56. [CrossRef]

2. Connolly, D.; Lund, H.; Finn, P.; Mathiesen, B.V.; Leahy, M. Practical operation strategies for pumped hydroelectric energy storage (PHES) utilising electricity price arbitrage. Energy Policy 2011, 39, 4189-4196. [CrossRef]

3. Chazarra, M.; García-González, J.; Pérez-Díaz, J.I.; Arteseros, M. Stochastic optimization model for the weekly scheduling of a hydropower system in day-ahead and secondary regulation reserve markets. Electr. Power Syst. Res. 2016, 130, 67-77. [CrossRef]

4. Ortner, A.; Graf, C. Multi-market unit-commitment and capacity reserve prices in systems with a large share of hydro power: A case study. In Proceedings of the 2013 10th International Conference on the European Energy Market (EEM), Stockholm, Sweden, 27-31 May 2013.

5. Ugedo, A.; Lobato, E.; Franco, A.; Rouco, L.; Fernandez-Caro, J.; Chofre, J. Strategic bidding in sequential electricity markets. Gener. Transm. Distrib. IEE Proc. 2006, 153, 431-442. [CrossRef]

6. Steeger, G.; Barroso, L.A.; Member, S.; Rebennack, S. Optimal bidding strategies for hydro-electric producers: A literature survey. IEEE Trans. Power Syst. 2014, 29, 1758-1766. [CrossRef]

7. Pérez-Díaz, J.I.; Chazarra, M.; García-González, J.; Cavazzini, G.; Stoppato, A. Trends and challenges in the operation of pumped-storage hydropower plants. Renew. Sustain. Energy Rev. 2015, 44, 767-784. [CrossRef]

8. Lobato, E.; Egido, I.; Rouco, L.; López, G. An overview of ancillary services in Spain. Electr. Power Syst. Res. 2008, 78, 515-523. [CrossRef]

9. Saraiva, J.T.; Heitor, H.; Correia, N.; Araújo, R. Ancillary services-The current situation in the Iberian electricity market and future possible developments. In Proceedings of the 2011 IEEE Trondheim PowerTech Conference, Trondheim, Norway, 19-23 June 2011.

10. ENTSO-E Working Group on Ancillary Services. Survey on Ancillary Services Procurement, Balancing Market Design. Available online: https:/ / www.entsoe.eu/Documents/Publications /Market\% 20Committee\%20publications/150127_WGAS_Survey_2014.pdf (accessed on 14 June 2017).

11. Deane, J.; Mckeogh, E.; Gallachóir, B. Derivation of intertemporal targets for large pumped hydro energy storage with stochastic optimization. IEEE Trans. Power Syst. 2013, 28, 2147-2155. [CrossRef]

12. Brijs, T.; Geth, F.; Siddiqui, S.; Hobbs, B.F.; Belmans, R. Price-based unit commitment electricity storage arbitrage with piecewise linear price-effects. J. Energy Storage 2016, 7, 52-62. [CrossRef] 
13. Kazempour, S.; Moghaddam, M.; Haghifam, M.R.; Yousefi, G.R. Risk-constrained dynamic self-scheduling of a pumped-storage plant in the energy and ancillary service markets. Energy Convers. Manag. 2009, 50, 1368-1375. [CrossRef]

14. Chazarra, M.; Pérez-Díaz, J.I.; García-González, J. Optimal energy and reserve scheduling of pumped-storage power plants considering hydraulic short-circuit operation. IEEE Trans. Power Syst. 2017, 32, 344-353. [CrossRef]

15. Chazarra, M.; Pérez-Díaz, J.I.; García-González, J. Value of perfect information of spot prices in the joint energy and reserve hourly scheduling of pumped storage plants. Electr. Power Syst. Res. 2017, 148, 303-310. [CrossRef]

16. Bonneville Power Administration. BPA Partners on Overhaul of World's Largest Turbines. Available online: https:/ / www.bpa.gov/news/newsroom/Pages/BPA-partners-on-overhaul-of-worlds-largest-turbines. aspx (accessed on 14 June 2017).

17. Alstom. Alstom Commissions World's Most Powerful Hydroelectric Units at Xiangjiaba Hydro Power Plant, in China. Available online: http:/ / www.alstom.com/press-centre/2013/7/alstom-commissions-worldsmost-powerful-hydroelectric-units-at-xiangjiaba-hydro-power-plant-in-china/ (accessed on 12 June 2017).

18. U.S. Bureau of Reclamation. Selecting Hydraulic Reaction Turbines; U.S. Government Printing Office: Washington, DC, USA, 1976; p. 54.

19. Merino, J.; Lopez, A. ABB Varspeed generator boosts efficiency and operating flexibility of hydropower plant. ABB Rev. 1996, 3, 33-38.

20. Nilsson, O.; Sjelvgren, D. Hydro unit start-up costs and their impact on the short term scheduling strategies of Swedish power producers. IEEE Trans. Power Syst. 1997, 12, 38-44. [CrossRef]

21. Chazarra, M.; Pérez-Díaz, J.; García-González, J. Optimal Operation of Variable Speed Pumped Storage Hydropower Plants Participating in Secondary Regulation Reserve Markets. In Proceedings of the 2014 11th International Conference on the European Energy Market (EEM), Krakow, Poland, 28-30 May 2014.

22. Pinto, J.; Sousa, J.; Neves, M. The value of a pumping-hydro generator in a system with increasing integration of wind power. In Proceedings of the 2011 8th International Conference on the European European Energy Market (EEM), Zagreb, Croatia, 25-27 May 2011.

(c) 2017 by the authors. Licensee MDPI, Basel, Switzerland. This article is an open access article distributed under the terms and conditions of the Creative Commons Attribution (CC BY) license (http:/ / creativecommons.org/licenses/by/4.0/). 